\title{
A STUDY OF ANATOMICAL VARIABILITY OF THE OMOHYOID MUSCLE AND ITS CLINICAL RELEVANCE
}

\author{
Rajalakshmi Rai, Anu Ranade, Soubhagya Nayak, Rajanigandha Vadgaonkar, \\ Pai Mangala, Ashwin Krishnamurthy
}

doi: $10.1590 / \mathrm{S} 1807-59322008000400018$

\begin{abstract}
Rai R, Ranade AV, Nayak SR, Vadgaonkar R, Pai MM, Krishnamurthy A. A study of anatomical variability of the omohyoid muscle and its clinical relevance. Clinics. 2008;63:521-4.

OBJECTIVE: The omohyoid muscle is a long, thin muscle consisting of superior and inferior bellies and an intermediate tendon, which runs obliquely in the lateral cervical region. The omohyoid is important in neck dissections because it is the surgical landmark for level III and IV lymph node metastases.

METHODS: In the present study, the anterior and posterior triangle of the neck was dissected in 35 male cadavers and observed for variations in the omohyoid bilaterally. Observations were focused on variations in number, attachments, and position of omohyoid.

RESULTS: Among the 35 cadavers studied, double omohyoid was present in one cadaver, inferior belly originated from the clavicle in three cadavers, superior belly merged with the sternohyoid in two cadavers, and the omohyoid received additional slips from the sternum in one cadaver. Standard attachment and position of the omohyoid was observed in the remaining cadavers.

CONCLUSION: Variations of this muscle are important because of its close relation to the large vessels and brachial plexus. Because of the direct adhesion of the intermediate tendon to the anterior wall of the internal jugular vein and its connection with it through a thin lamina of the pretracheal layer of the cervical fascia, the contraction of the omohyoid muscle has a direct effect on the lumen of this vessel.
\end{abstract}

KEYWORDS: Infrahyoid muscles. Sternocleidohyoideus. Neck dissection. Variations. Anomalies.

\section{INTRODUCTION}

The omohyoid muscle consists of superior and inferior bellies and an intermediate tendon, which runs obliquely in the lateral cervical region. The intermediate tendon is connected to the clavicle by a fascial sling. ${ }^{1}$ The omohyoid is important in neck dissections because it is the surgical landmark for level III and IV lymph node metastases. ${ }^{2}$ Lang stated that contraction of the omohyoid muscles causes dilatation of the penetrating neck veins and may be responsible for the creation of an air embolus after trauma

Department of Anatomy, Kasturba Medical College - Mangalore, Karnataka, India.

Email: rajalakshmirai@yahoo.co.in

Received for publication on March 04, 2008

Accepted for publication on April 10, 2008 or surgery in this region by tenting open these vessels. ${ }^{3}$ There are several reports of variations in the omohyoid: the superior belly is attached to the transverse process of the C6 anterior to the scalenus medius, ${ }^{4}$ double omohyoids ${ }^{5}$, absence of superior belly, ${ }^{6}$ and absence of inferior belly where the superior belly is attached to the clavicle. ${ }^{7}$ In addition, Hatipoglu et al. have reported the presence of an unfamiliar muscle cleido-hyoideus on the left side. ${ }^{8}$

It is necessary for clinicians to be aware of variations of the omohyoid because the inferior belly of the omohyoid is proximal to the brachial plexus trunks. According to Shih and Chuang, an anomalous omohyoid may cause Torticollis. ${ }^{9}$ Moreover, a hypertrophied omohyoid may irritate the brachial plexus. ${ }^{10}$ Thus, the aim of the present study is to describe the variations in morphology of the omohyoid and to discuss the clinical implications in neck dissection and other surgeries in the lower neck region. 


\section{METHODS}

The anterior and posterior triangle of the neck was dissected bilaterally in 35 male cadavers. The sternocleidomastoid was then reflected and observed for any variations in omohyoid. Observations were made on embalmed cadavers in the Department of Anatomy of Kasturba Medical College in Mangalore affiliated with Manipal University in India. The left cervical region was not available in three of the cadavers because the head was sagittally dissected for educational purposes.

\section{RESULTS}

Among the 35 cadavers studied, the variations observed are tabulated in Table I and explained below:

I. Double omohyoid - There was a superior omohyoid (Soh) and an inferior omohyoid (Ioh) on the right side. Both superior and inferior omohyoids originated from the transverse scapular ligament and after a distance of $2.1 \mathrm{~cm}$, were separated into two. The superior omohyoid had a normal superior belly and inferior belly with the intermediate tendon. The inferior omohyoid passed along the lower border of the superior and merged with the sternohyoid (Figure 1).

II. Cleido-hyoideus - The inferior belly was attached to the lateral part of the clavicle and the superior belly was attached to the lateral part of the body of hyoid bone with an

Table 1 - Variations observed in 35 cadavers included in this study

\begin{tabular}{llc}
\hline Types & Features & Percentage \\
\hline Normal & $\begin{array}{l}\text { Standard attachments of both superior \& inferior } \\
\text { bellies }\end{array}$ & $85 \%$ \\
\hline Type I & Double omohyoid (superior \& inferior omohyoid) & $3 \%$ \\
\hline Type II & $\begin{array}{l}\text { Cleido-hyoideus - Inferior belly from clavicle \& } \\
\text { superior belly attached to hyoid bone }\end{array}$ & $6 \%$ \\
\hline Type III & $\begin{array}{l}\text { Short OH - Inferior belly from clavicle \& superior } \\
\text { belly merging with Sternohyoid }\end{array}$ & $3 \%$ \\
\hline Type IV & $\begin{array}{l}\text { Superior belly receiving Slips from sternum with } \\
\text { normal inferior belly }\end{array}$ & $3 \%$ \\
\hline
\end{tabular}
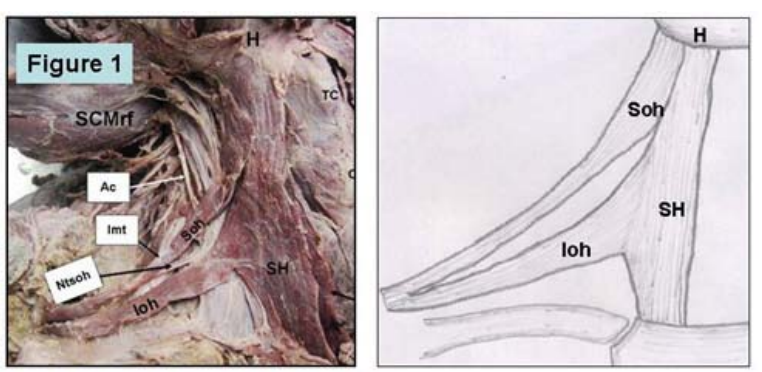

Figure 1 - Dissection of right cervical region showing double omohyoid: SH - Sternohyoid; Ioh - Inferior belly of Omohyoid; Soh - Superior belly of Omohyoid; $\mathrm{H}$ - hyoid bone intermediate tendon behind the Sternocleidomastoid muscle (Figure 2).

III. In this case, the omohyoid was comparatively shorter (Figure 3). The inferior belly ( $\mathrm{IOH}$ ) was attached to the clavicle 2.2 inches away from the medial end of the clavicle and a short superior belly $(\mathrm{SOH})$ merged with the sternohyoid ( $\mathrm{SH})$. The inferior belly and the intermediate tendon lay superficially to the internal jugular vein.

IV. Here the usual arrangement of omohyoid (superior and inferior belly with an intermediate tendon) was observed along with the intermediate tendon. But the superior belly received additional muscular and fascial slips from the upper part of the manubrium; this is represented by the term $\mathrm{OH}$. The inferior belly originated from the transverse scapular ligament and the medial end of suprascapular notch (Figure 4).
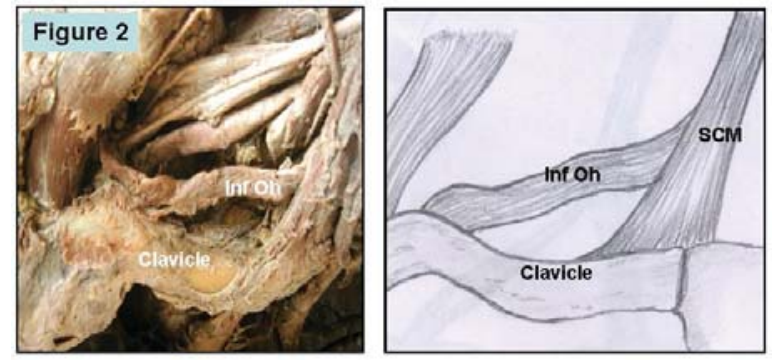

Figure 2 - Dissection of right cervical region showing inferior belly omohyoid from the Clavicle: SCM - Sternocleidomastoid; Inf Oh - Inferior belly of Omohyoid
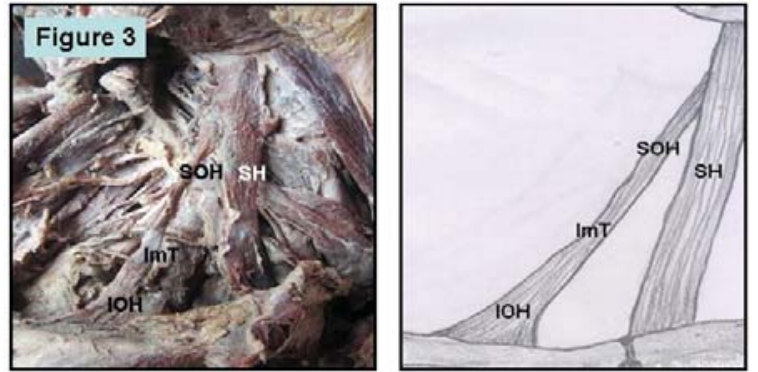

Figure 3 - Dissection of right cervical region showing inferior belly of omohyoid from clavicle \& suoerior belly merging qith the sternohyoid: $\mathrm{SOH}$ - Superior belly of Omohyoid; $\mathrm{SH}$ - Sternohyoid; IOH - Inferior belly of Omohyoid; ImT - Intermediate tendon
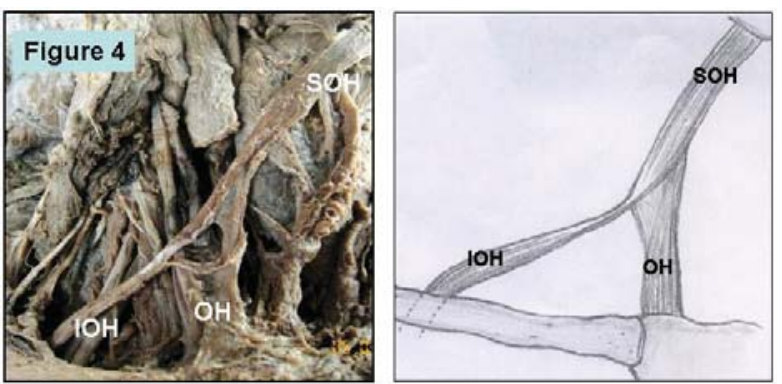

Figure 4 - Dissection of right cervical region showing fibres from sternum merging with the superior belly of Omohyoid: SOH - Superior belly of Omohyoid; IOH - Inferior belly of Omohyoid; OH - Fibres from sternum 


\section{DISCUSSION}

The omohyoid muscle is the best landmark for identifying the internal jugular vein (IJV); thus any variation in this muscle may increase the risk of injuring the IJV during surgeries in the lower neck region. ${ }^{11}$ Because of the direct adhesion of the intermediate tendon to the anterior wall of the internal jugular vein and their connection through a thin lamina of the pretracheal layer of the cervical fascia, the contraction of the omohyoid muscle has a direct effect on the lumen of this vessel. ${ }^{12}$ Having a common primordium with the sternohyoid muscle, the omohyoid muscle often varies in shape with regards to different insertion points of the superior and inferior bellies, and to the different positions of the intermediate tendon in relation to the internal jugular vein. $^{12}$

The incidence of omohyoid anomalies with respect to the origin, insertion, course, number of bellies, and surrounding muscles is high. ${ }^{13}$ There have been many reports of abnormalities in the superior belly including the origin and insertion of the belly, absence of the belly, multiple bellies, and adhesion of the belly to the sternohyoid muscle. ${ }^{14-17}$ These anomalies were classified into five types by $\operatorname{Loth}^{18}$ and six types by Miura et al. ${ }^{5}$ Loth considered the omohyoid to be a remnant of the sternocleido-omohyoid muscle. Miura et al. described a duplicated superior belly of the omohyoid with one portion inserting into the hyoid bone and one portion fusing into the lateral part of the sternohyoid muscle similar to our finding (Figure 3). These authors reported that this muscle is assumed to be a vestigial structure in humans reduced from the episterno-cleido-hyoideus muscle sublimes that are observed in lower types of vertebrates. Anderson has reported duplication of both the superior and inferior bellies on the left side of the adult male. ${ }^{19} \mathrm{He}$ theorized that the superior belly of the omohyoid muscle is a true infrahyoid muscle, whereas the inferior belly most likely shares a common embryology with the subclavius muscle. He separated the omohyoid into sternohyoid and recto-scapular components.

Although the omohyoid is one of the infrahyoid muscles, it differs from the other three muscles (sternohyoid, sternothyroid, and thyrohyoid) in its course. This is due to the formation process of the infrahyoid muscles. ${ }^{20}$ The infrahyoid muscles are formed from a muscle primordium occurring in the anterior cervical area. ${ }^{21}$ The muscle primordium is first divided into a shallow layer and a deep layer, which becomes the sternothyoid and thyrohyoid muscles. Although the shallow layer becomes the splenius spread in the cervical region, the intermediate area in humans is degenerated and the splenius is separated into the internal and external muscles. The internal muscle becomes the sternohyoid muscle and runs straight into the anterior cervical region. The lower part of the external muscle grows in the external and inferior direction and becomes the omohyoid, which runs obliquely in the lateral cervical area. ${ }^{21}$ Therefore, anomalies caused by the adhesion of the fetal omohyoid and the cleido-sterno-hyoideus are from primitive morphology of the splenius. ${ }^{15,16,22}$ It has been suggested that because the human omohyoid is degenerating, the incidence of anomalies is high. Unusual omohyoid forms described by Bergman et al. include: cleidofascialis, which originates from the middle third of the clavicle and inserts into the fascia colli (neck); cleidohyoideus, which originates behind the origin of the cleidomastoid part of sternocleidomastoideus and inserts onto the body of the hyoid bone; and hyofascialis, which originates from the hyoid and inserts into the omosternoclavicular fascia. ${ }^{23}$

Currently the use of infrahyoid myocutaneous flaps is a well-established alternative for reconstructing surgical defects. The supernumerary muscles, as double omohyoids (Figure1), can be utilized for muscle reconstruction. Wang et al. reported that infrahyoid myocutaneous flaps (IHMCFs) were used for the reconstruction of the tongue after resection of lingual carcinoma. ${ }^{24}$ The omohyoid muscle flap was transposed into the mucosal pocket and sutured to the vocal process for the treatment of bowed vocal folds. ${ }^{25}$ This procedure should be considered an option in treating highly bowed vocal folds. The wide variability of the position of the omohyoid muscle is likely to have implications for the surgical management of oral and oropharyngeal cancer, ${ }^{26}$ as would the short omohyoid muscle, as in our case (Figure 3). Compression of the internal jugular vein by the short omohyoid muscle may lead to modifications in intracerebral venous hemodynamics, which can be affected during yawning. ${ }^{27}$ This can be applied to one of our findings where the omohyoid was comparatively short (Figure 2) and in another case where the omohyoid receives slips from the sternum as well as the cervical fascia (Figure 4). Moreover, due to the direct adhesion of the intermediate tendon to the anterior wall of the internal jugular vein and their connection through a thin lamina of the pretracheal layer of the cervical fascia, the contraction of the omohyoid muscle has a direct effect on the lumen of this vessel. ${ }^{12}$ Because of the significance of the omohyoid in neck dissection as well as its close relation to the large vessels and brachial plexus, a better understanding of variations of this muscle is of paramount importance to head and neck surgeons. 


\section{REFERENCES}

1. Moore KL. Clinically Oriented Anatomy, third ed. Williams \& Wilkins. A Waverly Company, Baltimore, 1992. p.797.

2. Robbins KT, Medina JE, Wolfe GT, Levine PA, Sessions RB, Pruet CW. Standardizing neck dissection terminology. Official report of the Academy's committee for Head \& Neck Surgery and Oncology. Arch Otolaryngol Head Neck Surg. 1991;117:601-05.

3. Lang J. Clinical anatomy of the cervical spine. New York: Thieme. 1993. p. 29.

4. Tubbs RS, Salter EG, Oakes WJ. Unusual origin of the omohyoid muscle. Clin Anat. 2004;17:578-82.

5. Miura M, Kato S, Itonaga I, Usuy T. The double omohyoid muscle in humans: Report of one case and review of the literature. Okajima Folia Anat Jpn. 1995;72: 81-9.

6. Tamega OJ, Garcia PJ, Soares JC, Zorzetto NL. About a case of absence of the superior belly of the omohyoid muscle. Anat Anz. 1983;154:3942 .

7. Bolla SR, Nayak S, Vollala VR, Rao M, Rodrigues V. Cleidohyoideus. A case report. Indian Journal for the Practising Doctors. (2007-01-200702);3(6).

8. Hatipoglu ES, Kervancioglu P, Tuncer MC. An unusual variation of the omohyoid muscle and review of literature. Ann Anat. 2006;188:46972 .

9. Shih TY, Chuang JH. Fibrosis of the omohyoid muscle-an unusual cause of torticollis. J Pediatr Surg. 1998; 33:741-2.

10. Fiske LG. Brachial plexus irritation due to hypertrophied omohyoid muscle: a case report. J Am Med Assoc. 1952;149:758-9.

11. Kasapoglu F, Dokuzlar U. An Unknown variation of Omohyoid Muscle. Clin Anat 2007;20:964-65.

12. Ziolkowski M, Marek J, Oficjalska-Mlynczak J. The omohyoid muscle during the fetal period in man. Folia. Morphol. (Warsz). 1983;42:2130 .

13. Sasagawa I, Takahashi K, Igarashi A Mori H, Kobayashi K. A case of an abnormal bundle from the anterior margin of the right and left trapezius and the abnormality in the right omohyoid appeared in a cadaver. Shigaku. 1982;70:439-48.

14. Takano T, Adachi $\mathrm{H}$ On the anomalies in the infrahyoid muscles especially in the omohyoid muscle. Acta Anat Nippon.1954;29:5-6.
15. Takano T, Takaya M, Iizuka K. A statistical study of abnormal muscle of infrahyoid. Iwateidai Kaibou Gyouseki. 1955;2:113-24.

16. Sato Y, Oota Y, Yokota A La anomalio de M. omohyoideus ce Japanoj. Nichidai Igaku Z.1969;28:431-44.

17. Murakami M, Rokutanda A, Kikuchi N A rare case of abnormity in the lower belly of the omohyoid muscle. Kyushu Shika. Z 1971;25:1256.

18. Loth E Muskeln des halses. In: Beitrage zur Anthropologie der Negerweichteile. Streker and Schroder, Stuttgart. 1912. 58-73.

19. Anderson RJ. The morphology of the omohyoid muscle. J. Med. Sci. 1881;10:1-17.

20. Sukekawa R and Itoh I. Anatomical study of the human omohyoid muscle: Regarding intermediate morphologies between normal and anomalous morphologies of the superior belly. Anat Sci Int. 2006;81:107-14.

21. Lewis WH. The development of the muscular system. In: Manual of Human Embryology, 1st edn (Keibel F, Mall FP, eds). Lippincott, Philadelphia, 1910; p.454-522.

22. Buntine JA. The omohyoid muscle and fascia. Aust NZ Surg. 1970;40:86-8.

23. Bergman RA, Afifi AK and Miyauchi R. Illustrated Encyclopedia of Human Anatomic Variation: Muscular System: Omohyoideus, Sternohyoideus, Thyrohyoideus,Sternothyroideus. 1996. http:// www.anatomyatlases.org/AnatomicVariants/MuscularSystem/ MuscleGroupings/21Infrahyoid.shtml

24. Wang HS, Shen JW, Ma DB, Wang JD, Tian Al The infrahyoid musculocutaneous flap for reconstruction after resection of head and neck cancer. Cancer. 1986;57:663-8.

25. Kojima H, Hirano S, Shoji K, Omori K, Honjo I Omohyoid muscle transposition for the treatment of bowed vocal fold. Ann Otol Rhinol Laryngol. 1996;105:536-40.

26. Mizen KD, Mitchell DA. Anatomical variability of omohyoid and its relevance in oropharyngeal cancer. Br J Oral Maxillofac Surg. $2005 ; 43: 285-8$

27. Patra P, Gunness TK, Robert R, Rogez JM, Heloury Y, Le Hur PA et al. Physiologic variations of the internal jugular vein surface, role of the omohyoid muscle, a preliminary echographic study. Surg Radiol Anat. 1988;10:107-12 